\title{
Engaging with Fragile and Conflict-Affected States
}

\section{An alternative approach to theory, measurement and practice}

\author{
Michael Woolcock \\ CID Working Paper No. 286 \\ July 2014
}

(C) Copyright 2014 Woolcock, Michael; and the President and Fellows of Harvard College

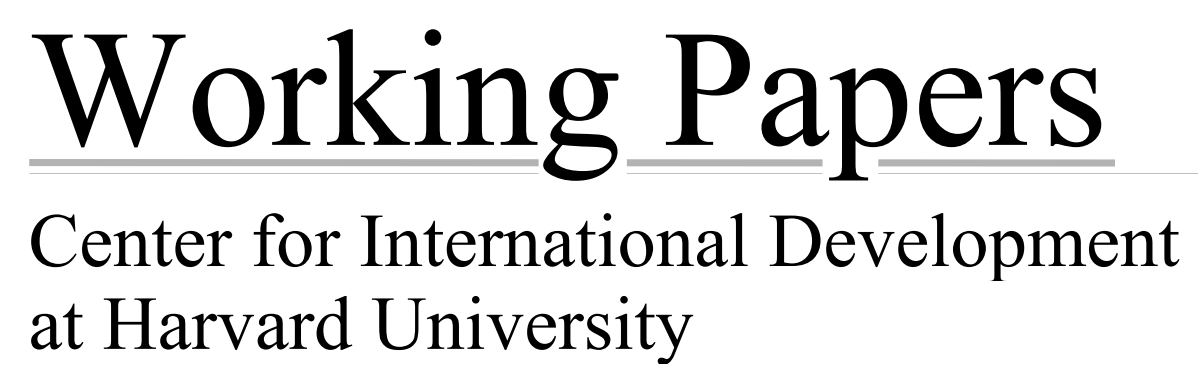


WIDER Working Paper 2014/097

\section{Engaging with fragile and conflict-affected states}

An alternative approach to theory, measurement and practice

Michael Woolcock*

July 2014 
Abstract: The coherence and effectiveness of engagement with the world's 'fragile and conflictaffected states'-beyond ethical imperatives and geo-strategic considerations-turns on answers to two vexing questions. First, on what defensible basis is any given country, at any given historical moment, deemed to be (or not to be) 'fragile'? Second, if a defining characteristic of state fragility is low levels of capability to implement core responsibilities, how can international agencies best support domestic public organizations to acquire capability? The first issue may appear to be a methodological one (wherein more and better data would provide a firmer empirical foundation on which to base key decisions) but any determination, especially of marginal cases, must also be grounded in a correspondingly comprehensive theory of change. Similarly, the optimal response to the second issue may appear to be importing technical and rigorously verified ('best practice') solutions, but in fact it is more likely to require a qualitatively different strategy, one able to experiment with alternative design specifications and adapt in real time to changing contextual realities (thereby iterating towards customized 'best fit' solutions). To this end, an alternative approach to the theory, measurement and practice of engaging with fragile states is outlined, in the spirit of rising concerns across the development community that prevailing strategies have demonstrably reached the limits of their effectiveness.

Keywords: conflict, fragile states, institutional change, measurement, security JEL classification: D73, O17, O19

Acknowledgements: The views expressed in this paper are those of the author alone, and should not be attributed to the World Bank, its executive directors or the countries they represent. My thanks to Joel Hellman (for the invitation to prepare this paper), Gary Millante (for several useful conversations on prevailing approaches to the measurement of fragility), Laura Bailey and Edie Bowles (on how these issue play out from a country management perspective), Frauke de Weijer, Lant Pritchett and colleagues from various organizations who are working in/on fragile states. Needless to say, given the sensitive nature of the issues and proposals discussed in this paper, all remaining errors of fact and interpretation remain wholly mine.

\footnotetext{
*World Bank, mwoolcock@worldbank.org

This working paper has been prepared within the UNU-WIDER project 'Building State Capability through Problem-Driven Iterative Adaptation (PDIA)' directed by Lant Pritchett and Matt Andrews, which is a component of the larger UNU-WIDER programme 'Foreign Aid: Research and Communication (ReCom)'.
}

\section{Copyright (C) UNU-WIDER 2014}

ISSN 1798-7237 ISBN 978-92-9230-818-6

Typescript prepared by Janis Vehmaan-Kreula at UNU-WIDER.

UNU-WIDER gratefully acknowledges specific programme contributions from the governments of Denmark (Ministry of Foreign Affairs, Danida) and Sweden (Swedish International Development Cooperation Agency-Sida) for ReCom. UNU-WIDER also gratefully acknowledges core financial support to its work programme from the governments of Denmark, Finland, Sweden, and the United Kingdom

The World Institute for Development Economics Research (WIDER) was established by the United Nations University (UNU) as its first research and training centre and started work in Helsinki, Finland in 1985. The Institute undertakes applied research and policy analysis on structural changes affecting the developing and transitional economies, provides a forum for the advocacy of policies leading to robust, equitable and environmentally sustainable growth, and promotes capacity strengthening and training in the field of economic and social policymaking. Work is carried out by staff researchers and visiting scholars in Helsinki and through networks of collaborating scholars and institutions around the world.

UNU-WIDER, Katajanokanlaituri 6 B, 00160 Helsinki, Finland, wider.unu.edu

The views expressed in this publication are those of the author(s). Publication does not imply endorsement by the Institute or the United Nations University, nor by the programme/project sponsors, of any of the views expressed. 
[1] is highly improbable that institutions could emerge smoothly from a gathering momentum of converging interests and an unspecified mixture of coercion and convention. We have too much experience of how easily they come apart and collapse. The thing to be explained is how institutions ever start to stabilize.

Mary Douglas, How Institutions Think (1986: 111)

All projects are problem-ridden; the only valid distinction appears to be between those that are more or less successful in overcoming their troubles and those that are not.

Albert Hirschman, Development Projects Observed (1967: 3)

Introduction

Whether and how to engage with the world's 'fragile and conflict-affected states' (FCS) is a central development issue of the early twenty-first century. The moral and strategic imperative to find constructive ways of undertaking such engagements is clear, and under minimally favourable conditions both public and private resources are (for the most part) readily available to realize them. Yet the basis on which a 'fragile' state is distinguished from a 'non-fragile' state-with all of the obvious implications this entails for the volume and type of development assistance available-remains disconcertingly (and perhaps inherently) far from precise. The World Bank, for example, deems a country to be 'fragile' if it (a) is eligible for assistance (i.e., a grant) from the International Development Association (IDA),1 (b) has had a UN peacekeeping mission in the last three years, and (c) has received a 'governance' score of less than 3.2.2 The basis of both the scores themselves and the 3.2 threshold, however, are increasingly recognized to be a poor guide to distinguishing between 'marginal fragility' situations, whether at the national or (especially) sub-national level. Moreover, even if a given country is 'fragile' by any reasonable definition and measure (e.g., Congo DR, Somalia), its status as a 'fragile state' does not axiomatically map onto a coherent theory of change, array of strategies or battery of instruments that international or domestic actors can readily deploy. Perversely, this very uncertainty can predispose risk-averse or overwhelmed agencies to double down on a narrow range of standardized 'tools', even if these imported 'solutions' are wildly discordant with prevailing realities and organizational capabilities (see Larson et al. 2013 on South Sudan).

Dissatisfaction with the prevailing definitions, measurement protocols and programmatic responses to state fragility is becoming increasingly widespread, as are calls for supportable alternatives. The World Bank's flagship World Development Report on conflict and security (World Bank 2011), for example, explicitly recognizes the dangers of mistaking 'form' for 'function'i.e., of importing uniform institutional 'blueprints' in the implicit belief that 'looking like a state' is a legitimate basis on which to presume that it will actually perform like one; 3 it argues for a departure from adopting standardized 'best practice' solutions to customizing 'best fit' responses.

\footnotetext{
1 IDA itself is a constituent member of the broader World Bank Group.

2 For the World Bank, most of the regional development banks and donors, 'governance' quality is measured by the Country Performance and Institutional Assessment (CPIA) index, which is a tool developed in-house by the World Bank over several decades (but has only recently been made publically available). See further discussion in this paper.

3 See Pritchett et al. (2013) for a detailed discussion of the mechanisms by which changes in 'form' is mistaken for changes in 'function' (a process they call 'isomorphic mimicry'), thereby perpetuating 'capability traps'-i.e., the structural inability of public organizations to improve their demonstrated ability to implement increasingly complex (and contentious) tasks, despite appearing to possess organizational designs (e.g., budgeting and procurement rules, anti-corruption laws, stately courthouses, detailed constitutions) that external observers may regard as exemplary.
} 
Similarly, a recent review by the World Bank of its portfolio of activities in FCS (World Bank 2013) concludes by calling for, among other things, the development of 'an alternative mechanism to define FCS status' (ibid.: 114) and crafting country assistance strategies 'tailored better to FCS, with clear ... contingencies for rapid adjustment if the country context changes' (ibid.: 115). Even so, it is tempting to see in these challenges answers that are primarily technical: more and better data across/within countries and sectors to solve the measurement problem, a more determined quest for 'tools' that 'work' (as verified by 'rigorous evidence') to enhance the likelihood of programmatic success. Aspects of such responses certainly have their place, but this paper argues that they are inadequate: at best they provide marginal improvement while at worst they are part of the problem (because they absolve decision makers of the harder task of engaging with the idiosyncrasies of particular country circumstances, and impose singular/standard metrics on countries seeking to chart their own path from fragility). What might an alternative response look like? How might robust political support for it be secured within international agencies and among leaders of national (and sub-national) ministries? How and by whom might it be implemented? This paper seeks to outline the contours of an initial response to these challenges, but in so doing - and in keeping with the spirit that informs its key recommendations_-overtly encourages others to contribute and offer subsequent iterations.

The paper proceeds as follows. Following this introduction, Section 2 briefly reviews the current basis on which a country's status as a 'fragile state' is determined, and assesses the various critiques that have been offered of this approach. If a state has been deemed to be 'fragile', this section also considers the dominant modalities of assistance that have been deployed in response to this status, and why oft-stated concerns about the modest effectiveness of these modalities have remained largely impervious to reform or to displacement by plausible alternatives. On the basis of this analysis, Section 3 proposes both a different theory of change and thus a different approach to determining not just whether a state is fragile (categorically) but in what ways and to what extent it is/has been/might be fragile over time. Section 4 builds on this framework to propose a different kind of development assistance strategy that might be better suited to the central problem of low state capability for implementation in fragile states, with a particular focus on the potential utility of an evolving approach known as 'Problem-Driven Iterative Adaptation' (PDIA) (see Andrews et al. 2013). Section 5 concludes.

\section{Defining and responding to 'fragile' states: a brief review of current practice}

The Bretton Woods institutions came into existence in the 1940s with an explicit mandate for 'reconstruction' as well as 'development'. 4 The first of these terms accurately defined the vast majority of the World Bank's initial work in war-torn Europe, but it is only again in the early twenty-first century that 'reconstruction' has been so explicitly invoked as a programmatic rationale on which to focus activity in what are now called FCS (World Bank 2011). Although for many years the topics of 'governance', 'violent conflict' and even 'corruption' were regarded as either too sensitive or beyond the World

Bank's mandate or expertise (indeed, some still hold this view), since the mid-1990s these issues have moved from the margins to the mainstream: in the current reorganization of the World Bank, 'Fragility, Conflict, and Violence' are regarded as highest-priority topics, with president Jim Y. Kim declaring that the World Bank should be sending its 'best people to the toughest places'.

It is beyond the scope of this paper to explain this transformation, except to note that conflict and the broader issues to which it gives rise are hard to ignore in an interconnected 'global' age.

\footnotetext{
4 Lest we forget, and as the World Bank (2011) reminds us, the largest constituent member organization of the World Bank Group is still today called the 'International Bank for Reconstruction and Development' (IBRD).
} 
The tragic plight facing millions of poor and displaced people, the world's heightened awareness of it, and a security imperative in which instability and bloodshed 'there' can-and/or is perceived to-have immediate consequences 'here' (for the military, for migration flows, for service provision), combine to create a powerful political consensus for action. Among both development scholars and practitioners (if not always the general public), few now question either the empirical reality that the 'bottom billion' often live in 'dangerous places' 5 and that high importance should be accorded to responding to such contexts in ways that are both effective and ethical. 6

As is often the case in development, however, the movement from moral, political and strategic consensus to policy action is far from straightforward. Even when adequate material resources may not be the 'binding constraint', hard decisions still need to be made about who is and is not eligible for assistance, and on what basis. Having satisfied eligibility requirements, a particular programmatic or policy intervention (or array of interventions) needs to be determined, designed and approved; and then, crucially, a robust implementation apparatus must be assembled to carry it out. Upon any disbursement, equally difficult decisions need to be made regarding whether resources were deployed in ways not merely in compliance with formal bureaucratic rules but whether they achieved the desired 'results' (net of other contributing or hindering factors). Each of these administrative tasks is hard enough - and controversial enough - in relatively peaceful contexts with a long history of public administration and civic engagement (such as India; see Gupta 2012), let alone in countries that have oscillated for decades between peace and civil war, where residents have little conception of 'citizenship' and no lived experience of even a minimally 'benign'7 social compact governing their relations with each other and collectively with the state and private sector. It is harder again in 'new' states (such as South Sudan), where almost everything pertaining to public action may literally need to be learned 'from scratch'.

Policy action begins with a definition, and while different development organizations have slightly varied emphases they clearly share a common focus. The OECD (2012: 15), for example, defines a fragile state (or region) as one having 'weak capacity to carry out basic governance functions, and [which] lacks the ability to develop mutually constructive relations with society. Fragile states are also more vulnerable to internal and external shocks such as economic crises or natural disasters'. Similarly, the World Bank defines a fragile state as one 'facing particularly severe development challenges: weak institutional capacity, poor governance, and political instability. Often these countries experience ongoing violence as the residue of past severe conflict'. This formal definition gives rise to a corresponding administrative definition, in which — as noted above - a state is deemed 'fragile' if it is a low-income country or territory, IDA eligible (including those countries which may currently be in arrears), with a Country Policy and Institutional Assessment (CPIA) score of 3.2 or below, and has had a UN peacekeeping mission present at any time in the last three years. (Those countries for which CPIA data is not available are automatically included.) Countries are considered 'core' fragile states if their CPIA is below 3.0 or there is no data available; countries are considered 'marginal' fragile states if their

\footnotetext{
5 This is a central thesis, for example, in the influential work of Paul Collier (even if, strictly speaking, most of the world's poor now live in middle income countries such as China, Indonesia and India). See also OECD (2012: 12), which asserts that fragile states 'are home to an increasing proportion of the world's poor'. The World Bank estimates that by 2030 approximately 40 percent of the world's poor will live in FCS.

6 During this period scholars have also ramped up the quality and volume of their contributions to the topic of state fragility, building on the initial work of Helman and Ratner (1992) and Zartman (1995). Even a passing summary is beyond the scope of this paper, though the most salient contemporary sources are World Bank (2001), Fukuyama (2004), Eizenstat et al. (2005) and Ghani and Lockhart (2009); see also Stewart and Brown (2009), UNDP (2009) and the important thinking reflected in Porter et al. (2011).

7 The importance for development of social relations between citizen and state being (or becoming increasingly) 'benign' comes from Bayly (2004).
} 
CPIA score is between 3.0 and 3.2. Such an approach yields a current list of 35 countries (see Annex 1), which explicitly or implicitly, largely become the basis for determining fragility used by all the multi-lateral development banks and most donors. The CPIA score for each country at any particular moment is essentially determined by asking country experts for their views on sixteen governance issues (e.g., corruption, contract enforcement, etc.). As its very title suggests, however, the CPIA was not set up to determine state 'fragility', but became a default proxy measure for fragility when analysts discovered that the CPIA initially seemed to be strongly correlated with other (less comprehensive) indicators of fragility. Over time, however, as a recent review by the World Bank itself has acknowledged (World Bank 2013), there has been an increasing divergence between the CPIA and specific instances of fragility (or resilience): this is a central methodological reason why the World Bank (and others) are now calling for 'an alternative mechanism to define FCS status' (World Bank 2013: 114).

Beyond the official development agencies, various independent organizations have sought to fill this space in recent years. Foreign Policy magazine, most visibly, has teamed with the Fund for Peace to publish an annual 'Failed States Index', which ranks countries on the basis of 12 constituent measures. ${ }^{8}$ Data produced the 'Quality of Governance' group in Gothenburg has been widely used for similar purposes, as has the Bertelsmann Transformation Index and the Center for International Development and Conflict at the University of Maryland. Importantly, since 2011 a core group of 'failed states' known as the G7+ have come together to provide their own definition of 'fragility'; they have succeeded in crafting their own New Deal' policy platform that has been broadly supported (by donors and other fragile states), and in arguing strongly for developing country-specific indicators (rather than promoting conformity with singular global measures) to chart progress towards stability and resilience (see G7+2013).

The recent profusion of 'governance indicators' produced by a range of advocacy, academic and aid organizations, however, both helps and hinders the task of responding effectively to failed states. It helps, because more and better data is generally useful for grappling with inherently vexing issues, and no data at all exists on several fragile states. Similarly, when several methodological approaches arrive at roughly consistent designations of which states are 'fragile', both researchers and policy makers can be more confident in their decision-making. To the extent a major purpose of any widely published 'index' or 'ranking' in any field is to generate attention from policy makers and the public, then good-enough measures of 'failed states' helps to draw attention to a pressing issue. But it can also hinder the task to the extent it gives the decision-making process an allure of sophistication while absolving actors of the need to engage substantively with the detailed idiosyncrasies of marginal or specific cases-Pakistan, for example, or regional areas within Nigeria and Russia. Moreover, even the surest indicators applied to unambiguous cases do not provide a guide to context-specific policy action; the significance of indicators (and any changes therein over time) must be interpreted in the light of a theory, as must any 'policy implications' to which they might give rise. 10 Sudan has a low CPIA

8 Further details on the content of (and methodology underpinning) the 'Failed States Index' is available at http://www.foreignpolicy.com/articles/2013/06/24/2013_failed_states_interactive_map. The FSI's 12 component indicators are: demographic pressures; refugees/IDPs; group grievance; human flight; uneven development; economic decline; delegitimization of the state; public services; human rights; security apparatus; fractionalized elites; external intervention. Though these formal 'indexes' of relatively recent provenance, it is interesting to note which countries were deemed 'failed states' (at least in the academic literature) 20 years ago that now are not (e.g., Cambodia).

9 The definition of state 'fragility' adopted by the G7+ (2013: 4) is 'a period of time during nationhood when sustainable socio-economic development requires greater emphasis on complementary peace-building and statebuilding activities such as building inclusive political settlements, security, justice, jobs, good management of resources, and accountable and fair service delivery'.

10 Andrews (2008) provides a critique along these lines of the World Bank's widely-cited governance indicators. 
score, for example, and the highest ranking on the broader 'failed states index', but this does not - in and of itself-provide a guide to policies or practices that might plausibly respond to Sudan's particular concerns. Indeed, if indicators are themselves read crudely as guides to policy-e.g., if a poor score on 'debt management' becomes a basis for enacting changes that merely enable a country to get a better debt management score-then they can mask debilitating weaknesses in other areas (Papua New Guinea) and/or perpetuate practices contributing to the consolidation of capability traps (Pritchett et al. 2013). That is, seemingly impressive changes that shape how debt management is 'scored' might be enacted that have little or no bearing on improving how debt is actually managed.

More and better data, in short, is a necessary but insufficient condition for both distinguishing between different types of state fragility and, having deemed a given state 'fragile', for determining what course of policy action should be pursued. This latter aspect is a crucial issue. Even in states that are unambiguously fragile by any measure-such as Afghanistan (de Weijer 2013) or South Sudan (Larson et al. 2013) — the international community has a far-from-stellar record of accomplishment. The lead organizations undertaking the task of 'state building' in these countries routinely espouse the virtues of 'taking context seriously' and the importance of 'local participation', but as these authors' accounts amply demonstrate, there is a wide and persistent gap between de jure and de facto practice: despite what the planning documents might say, the reality is that implementing agencies work to tightly scripted programmes that (a) look remarkably similar across otherwise vastly different contexts, (b) justify programmatic action on the basis of what is deemed to have 'worked' elsewhere, (c) allow little space for local discretion and innovation, or learning from prevailing variation, and (d) follow time horizons that are too short, expecting 'success' ('results') at historically unprecedented rates. ${ }^{11}$

Departing from this unhappy but ubiquitous reality cannot be solved by generating better data, dispersing more money, hiring/retaining 'the right people' or enhancing the quality of 'capacity building' programmes (i.e., training of individuals), even if all these factors surely matter. A broken system (or perhaps a system that never worked in the first place) cannot be fixed by tinkering with its constituent elements; the ecosystem within which the system itself is embedded is the problem that needs to be reimagined and alternatives enacted. Far from claiming knowledge of a fully instantiated alternative, the sections that follow nonetheless dare to sketch some broad contours of what a component of it-in particular the component focused on distinguishing between different types and degrees of fragility-might begin to look like; more importantly (and in keeping with its own emergent principles), it begins by outlining what this alternative seeks to do.

\section{Theory and method underpinning an alternative approach}

As Milante (2013) correctly notes, the prevailing approach to measuring state fragility has been decidedly deductive: countries scoring below 3.2 on the CPIA measure are 'fragile'; Country X scores below 3.2; thus Country $\mathrm{X}$ is fragile. Most recently, proposals have been made to construct a more extensive battery of 12 'Post Conflict Performance Indicators' (PCPI), 12 but the abiding logic remains the same. As argued above, more and better data is necessary but

\footnotetext{
11 Andrews (2013) documents that these practices are hardly confined to engagements in fragile state; they amount to a veritable business-as-usual modality for a host of development agencies, and especially the World Bank.

12 The PCPI's 12 component indicators are: macroeconomic management; debt management; functioning of budget administration; business environment; human resource building; vulnerable groups, gender, social cohesion; capacity of public administration; rule of law and personal security; transparency and accountability; security; management of conflict and recovery; peace-building.
} 
insufficient; the key to progress is a different theory of change. Before outlining such a theory, however, it helps to begin by providing a concrete sense of how this theory would change the process of determining state fragility and (thus) how the responses to which it gives rise differ from prevailing practice.

The passages that follow propose a three-stage process of assessing state fragility (see Box 1 for a brief summary). The first stage entails arraying countries across a distribution of fragility with upper bounds (above which one is 'not fragile') and lower bounds (below which one is 'clearly fragile'), with 'marginally fragile' countries in between. The means proposed for doing so is not fundamentally different from the current approach (i.e., using available governance indices), except that a higher and lower bar is set than at present (an upper bound of 3.5 on the CPIA scale, a lower bound of 3.0), thereby creating a slightly larger pool of 'marginally fragile' and 'clearly fragile' states. The second stage seeks to work with this larger pool of countries to more closely interrogate the 'marginally fragile' states to make more refined judgments about the specific trajectory and severity of fragility each is experiencing, and, importantly, how its fragility has varied over time and (where possible) within the country itself. This stage seeks to transition from the prevailing 'static' model of fragility to a 'dynamic' one, in which a key consideration for donors is how far and for how long a country has been below (or perhaps temporarily above) the formal fragility threshold (see Figure 1). The third stage entails drawing on available historical, political and cultural sources to compile a country case study, 13 which in turn is used as part of a country dialogue (and country-specific fragility indicators) to discern which forms of assistance are most needed and supportable. (These country cases also serve as 'live' documents that are updated as necessary; they also form part of the historical-and hopefully public-record of what donors and governments have negotiated and undertaken.) The overarching objective of this three-stage approach is to harness the full range of available quantitative, qualitative, historical and 'time series' data, between and within countries, and to do so in active dialogue with a theory of change, in order to facilitate the crafting of response strategies that are tailored to the specific characteristics of the state in question. Let us address each stage in turn, and in more detail.

\section{Box 1: Overview of a proposed process for assessing state fragility}

Stage 1: Use existing public governance data (e.g., CPIA, but perhaps complemented with additional sources) to assign countries to one of three categories across a distribution of fragility with upper and lower bounds: 'clearly non-fragile', 'marginally fragile', 'clearly fragile'.

Stage 2: Further examine the 'marginally fragile' states by using available data on state capability (and other relevant governance variables) to assess (a) trajectories of change over time and (b) subnational variation, the better to identify particular types and degrees of state fragility (see text and Figure 1 for further discussion).

Stage 3: Compile 'live' (i.e., regularly updated) country case study narratives that draw on historical, cultural, political and social analyses to identify the specific ways in which a given country is 'fragile'; this document becomes the basis for a sustained in-country policy dialogue that begins the process of nominating and prioritizing specific problems (and, in time, possible solutions).

13 The country cases would have the same length, content and tone, for example, of those produced periodically by The Economist Intelligence Unit. It should also seek to incorporate suggestions (including indices) that countries themselves, and the $G 7+$, propose. 
Figure 1: A three-stage process for assessing state fragility

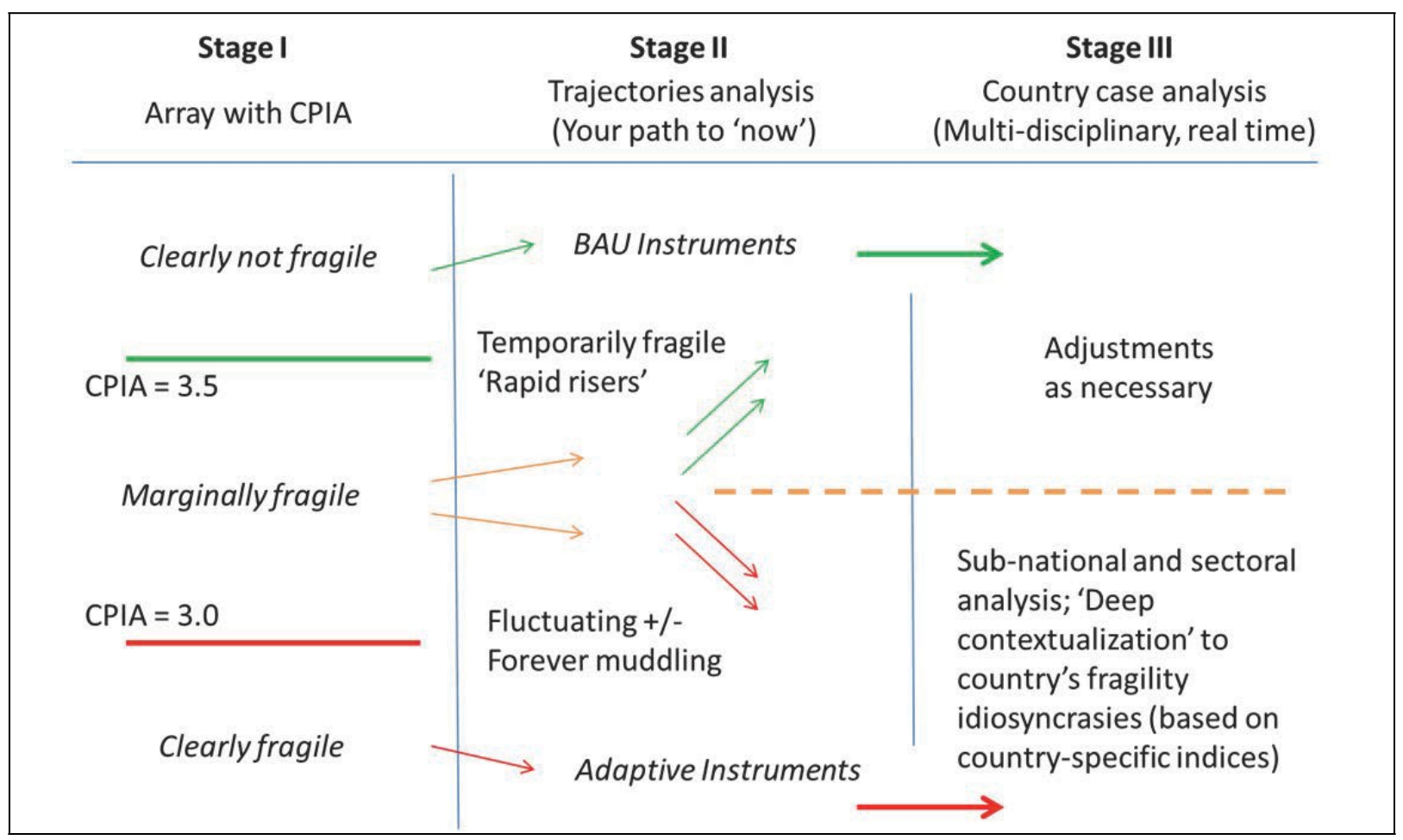

Source: Author's compilation.

Stage 1: Use existing governance and fragility data-which is steadily improving in both quality and scope - to assign developing countries under consideration to one of three categories: 'not fragile', 'marginally fragile' or 'clearly fragile'. Rather than creating yet another 'index', analysts could work with (say) the three or four most widely recognized datasets to rank order each country: those countries deemed 'clearly fragile' would be those that consistently appeared in (say) the bottom 20 in each ranking, while those consistently above the threshold would obviously be 'not fragile'. For all its acknowledged limitations, the CPIA is what we have and what most major development agencies look to; the proposal here is that we stick with it for now, and spend our energies on complementing the CPIA with additional analytical and methodological tools rather than seeking in vain to compile yet another 'new and improved' index of fragility. As discussed above, it is of course desirable to have more and better CPIAtype data, but the absence of that data at present is not itself the binding constraint on determining fragility or crafting context-specific policy responses.

The proposal here also suggests raising the current 'threshold' (or upper bound) on the CPIA distribution to 3.5 , in order to create a larger initial set of 'marginally fragile' states. (This list would be narrowed down in Steps 2 and 3.) The reason for doing so is two-fold. First, while any upper or lower bound is somewhat arbitrary, there needs to be a mechanism for accommodating the fact that a country could be technically rated 'non-fragile' because it has a CPIA score of 3.3, but has so only because this is an average compiled across the constituent/component metrics of the CPIA that in fact masks quite disconcerting fragility in key sectors. Papua New Guinea, for example, rates quite highly in its technical ministries (such as finance, macroeconomic indicators) but its high scores in these domains generate a high-enough overall average that severe weaknesses in the security and service delivery sector can be overlooked (see Bulman and Batten 2012 for an excellent discussion). This problem does not go away by raising the upper bound, but it at least minimizes the risk of 'false negatives' (i.e., of declaring a country 'non-fragile' when 
it clearly is). Second, per the discussion below, graduation out of fragility, while unambiguously welcome, can be precarious: to ensure that initial progress is consolidated, raising the upper bound to 3.5 reduces the likelihood that both domestic actors and the international community congratulate themselves prematurely.

Stage 2: Having identified both 'marginally fragile' and 'clearly fragile' states, the next analytical task is to determine what type of fragility they are experiencing, and how this fragility varies over time and space (i.e., within the country itself, where possible.) The very definition of a fragile state will mean that it most likely struggles to collect reliable and comprehensive data on itself; this is a difficult logistical and political task for any country (Jerven 2013). Even so, the principles to try to establish here are two-fold. First, that the abiding public narrative of fragile states cannot be sustained by endless litanies about their status as 'basket cases'-in even the most unlikely places, someone somewhere has somehow figured out how to do something relatively well (e.g., deliver the mail, educate children, maintain roads), and this can be a powerful source of local learning 14 as well as accurate 'good news' for media purposes. The second principle is that a national average is inherently accompanied by a standard deviation; as such, variation can occur across sectors, groups and space (i.e., hospitals might be tolerable even if schools are hopeless; women may do significantly better/worse than men; northern/temperate regions may be better than southern/tropical ones, etc.). Again, the key point of such analyses is to stimulate domestic political deliberation about the forms and sources of this variation, as a basis for identifying (and as necessary celebrating and replicating) 15 local initiatives that have succeeded, perhaps against all odds. The best (though not only) source of 'lessons' for what might work to enhance capability in 'fragile' states is successful instances already occurring within the context itself.

Analyses of this kind at the sub-national level can be complemented by assessing a 'marginally fragile' state's 'capability trajectory' over time. This would help distinguish, at a given moment, between countries with otherwise similar scores but on quite different paths (see Figure 2, and specific example of different capability trajectories in Annex 2); e.g., those who are consistently 'fragile'; usually resilient but temporarily 'fragile'; oscillating in and out of 'fragility'; historically 'clearly fragile' but actually getting better, etc. This approach enables analyses of fragility to be dynamic rather than static. Put differently, it matters how a country got to its present condition: where it is likely to go in the future is highly likely to be shaped by its recent past, and thus a current CPIA score of ' 3.1 ' from a country that has been mostly stable but just recently become fragile (e.g., Mali) should be distinguishable from a country that also received a CPIA score of '3.1' but for much of the last 20 years has been much lower (e.g., Sierra Leone, which is poisedwith much justifiable acclaim - to soon be declared a non-fragile state). Similarly, countries such as Lao People's Democratic Republic have oscillated in and out of fragility, while Haiti has been fragile for centuries: a trajectories analysis would help to distinguish between these different cases, and on that basis provide a better sense of what kinds of assistance might be needed. It would suggest that Haiti, for example, might need quite different forms of assistance from the international community than Mali or Sierra Leone.

\footnotetext{
14 This is the central insight of the 'positive deviance' approach to social learning (see Pascale et al. 2010). In public administration, variants on this approach have been deployed as part of the 'Successful Societies' programme at Princeton (see http://www.princeton.edu/successfulsocieties/), and the 'Institutions Taking Root' study conducted by the World Bank (Barma et al. 2013).

15 See Woolcock (2013) on the limits of generalizing development policy lessons across scale, groups, space and time, and the specific role that case studies can play when assessing the likely efficacy of 'complex' interventions in novel contexts.
} 


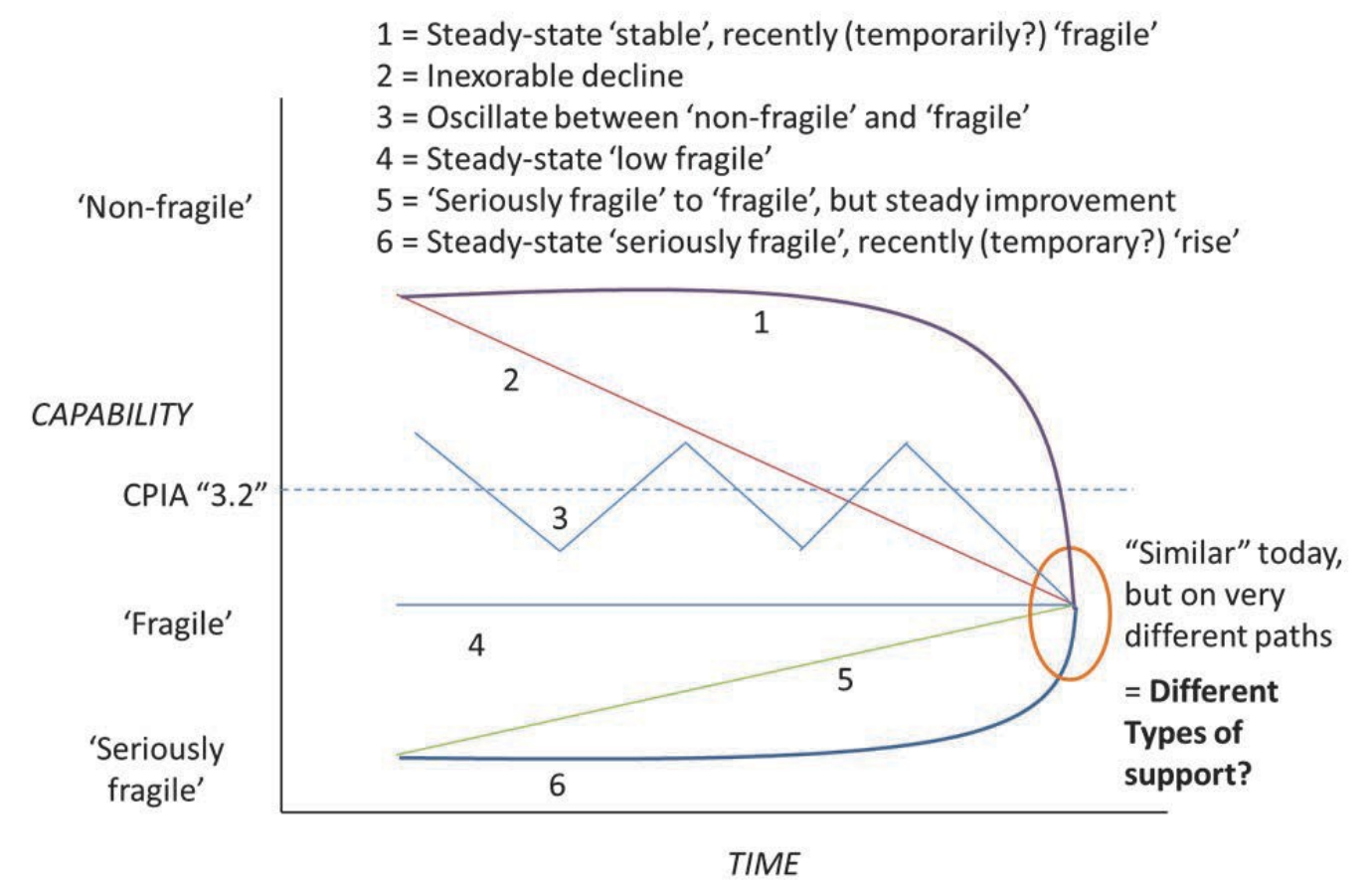

Source: Author's compilation.

Stage 3: The decision tools thus far have been largely quantitative; in this final stage, the goal is to actively incorporate 'qualitative' insights—from history, anthropology, sociology, journalism and (crucially) seasoned country practitioners - to compile live ('real time') country case studies. The idea (hope) is that participants making key decisions would engage with these case studies as part of a broader country dialogue to help inform key policy decisions about the specific types of development assistance that make the most sense, given the particular types of ways in which a given state is 'fragile'. If unhappy countries, like Tolstoy's unhappy families, are unhappy in their own way, there needs to be a specific formal mechanism by which the idiosyncrasies of a given fragile state become part of the decision-making apparatus used by domestic and international actors. Compiling country case studies-along with sector-specific and sub-national cases-can be a fruitful basis on which legitimate and context-specific approaches are forged.

\section{The theory of change on which the above is based}

The implications of 'the data' are never self-evident; they must be interpreted in the light of a theory. If there is a coherent theory informing current practice-not only in fragile states but in developing countries more generally-it is accelerated modernization via transplanted best practice; that is, intensifying the process of acquiring capability for implementation by adopting those organizational templates deemed (by experts) to work elsewhere.

An alternative worthy of the name must be grounded in a coherent theory of change, one that explicitly recognizes how long and difficult (even violent) has been the process by which humans have created public organizations charged with carrying out extraordinarily complex tasks: bounding elite authority, managing natural resource wealth, disproportionately taxing the wealthy, educating millions of children, regulating local stores to multi-national corporations, making the trains run on time. Acquiring and learning the organizational capability to undertake 
such complex tasks historically has taken decades (if not centuries16), but if development agencies focus on or reward only visible changes to the appearance (as opposed to the demonstrated functionality) of the designated public organizations, they can perpetuate what might be called a capability trap (Pritchett et al. 2013).

Helping fragile states escape from capability traps involves pursuing development interventions based on a very different set of principles from those characterizing current practice, not least in fragile states themselves. These interventions should (1) aim to solve particular problems in local contexts (as opposed to transplanting pre-conceived and packaged 'best practice' solutions), (2) through incremental processes of 'muddling through' that facilitate positive deviation (as opposed to designing projects and programmes and then emphasizing that agents implement them exactly as designed), (3) involving active, ongoing and experiential learning and the feedback of lessons into new solutions (as opposed to enduring long lag times in learning from ex post 'evaluation'), and (iv) engaging broad sets of agents to ensure that reforms are viable and relevant-i.e., politically acceptable and practically possible (as opposed to promoting the 'top down' diffusion of innovation). This approach has been called PDIA (Andrews et al. 2013).

A legitimate question to ask at this stage is whether PDIA itself requires minimal levels of capability to be successfully implemented. Perhaps, but building such capability is both possible and desirable (see below); indeed, it is a defining feature of development itself. The broader point is that decision makers need to be given (or themselves create) a robust authorizing environment in which to begin the process of articulating and implementing a different approach, one committed to building the capability of local teams to identify and prioritize problems, to assess the current nature and extent of these problems, to interrogate how positive change is being achieved, and to share this with others through an indigenous community of practice.

\section{Applying problem-driven iterative adaptation to fragile/conflict-affected states}

PDIA makes no claim to be the way in which development initiatives should be conducted in fragile and conflict-affected states; neither does it claim to be wholly 'new' as a strategy for enhancing the capability for implementation. ${ }^{17}$ It does claim, however, to have a coherent basis on which to distinguish between different types of development problems, and to help craft a more appropriate match between types of problems and types of solutions.

Our aim is to use PDIA methods in particular interventions, and to gather accounts of where they may already have been introduced, the better to learn from the grounded experiences of others and to adapt/update/refine PDIA accordingly. As such it is an ongoing process to which we actively encourage readers to contribute, especially those working in fragile states. Work along these lines has already been conducted in the fragile states of Solomon Islands and Sierra Leone, where teams of local researchers have been actively engaged in documenting changes in the nature and extent of conflict as a basis for contributing to a national policy dialogue. Policy debate about these issues would otherwise largely be conducted on an anecdotal basis, but using local researchers to generate local knowledge using local indicators has been central to identifying forms and source of local variation, in crafting a credible basis for reforms, and to

\footnotetext{
16 Former British Prime Minister Gordon Brown has quipped that the hardest part of building the rule of law is the first 500 years.

17 On the similarities and differences between PDIA and other contemporary approaches to development practice and institutional innovation (e.g., 'design thinking'), see Woolcock and Garrity (2013). PDIA's intellectual pedigree draws on the earlier work of (among others) Charles Lindblom, Albert Hirschman, Aaron Wildavsky, Merilee Grindle, David Korten, and Dennis Rondinelli.
} 
enhancing the legitimacy of international actors, whose role in these matters has been to facilitate rather than pre-determine what might be done.

Such an approach need not be limited to conflict issues per se. In Sierra Leone, for example, a team engaged with health services reform has sought to experiment at the front-lines with alternative modalities of provision, using real-time monitoring data to help decision makers identify what seems to work, where and why (see Hall et al. 2014). Routinizing such approaches to reform is a qualitatively different way of operating, but in the case of Sierra Leone comes as a result of many years (nearly a decade) of working with local researchers to build their capability for such tasks. Similar work is now being pioneered in Liberia and Papua New Guinea, but there too it is likely to require deep commitment on the part of country teams to building both the capability of local organizations but also sending sustained and credible 'signals' about how policy dialogue is to be practiced.

A similar arc has been followed with work in the Solomon Islands, a post-conflict country also currently deemed to be a 'fragile state'. There, the World Bank's 'Justice for the Poor' team has been extensively involved in conducting local level research on the nature and extent of disputes surrounding land, extractive industries and tourism-industries which are a mainstay of the Solomon Islands economy but also a long-standing source of contention with local communities (Goddard 2010), many of whom accord little salience to the national government as an impartial arbiter of such disputes. Communities themselves, moreover, often become internally (and intergenerationally) divided as these disputes evolve, the offer of millions of dollars for access to communal lands exposing and exacerbating tensions as to which social group can claim a legitimate juridical claim to hereditary 'ownership' of the land in question. Absent formal documentation, disputes over land ownership - and subsequent access; confusion stemming from the notion that land itself can be 'sold' in a commercial sense, with the new 'owners' having exclusive rights to the fruits of the land and thus the right to forcibly restrict access to it by nonowners, can be a subsequent source of conflict-quickly transcend the capability of the prevailing juridical system, with claims and counterclaims being made in a form that the state cannot 'see' (see Scott 1998) and thus cannot readily reconcile. The 'Justice Delivered Locally' project in the Solomon Islands has been built on an empirical platform that attempts to document the types and degrees of local conflict stemming from these disputes (see Allen et al. 2013), the findings themselves becoming open information that contributes to (a) the public process of political deliberation wherein (more) equitable resolutions to these disputes are sought, and (b) a platform on which broader policy responses to them can be identified, prioritized and customized. Such research is thus not merely adding to a fully-fledged and functioning legal/political system; it is helping imagine and create the initial capability on which such a state may hopefully emerge.

\section{5}

\section{Conclusion}

The factors predisposing a country to fragility and conflict may be many and varied, and a very different set of factors-i.e., not merely the same factors working in the opposite directionmay shape that country's pathways into and out of fragility. 18 Such considerations complicate,

\footnotetext{
18 More formally, these characteristics would lead some social science methodologists to classify 'fragility' as an asymmetric variable-i.e., one in which outcomes observed when that variable moves in a certain direction (e.g., from absence to presence of 'democracy') are not mirrored when the corresponding change occurs in the opposite direction (from presence to absence of 'democracy'); see Goertz and Mahoney (2012: 64-74), drawing on Lieberson (1985). At first glance this may seem a minor academic point, but it has important implications for practitioners engaging in countries that move relatively frequently into and out of 'fragility'. For example, can a single strategy
} 
but need not compromise, the development community's need for defensible measures grounded in coherent theories for determining which countries are (or are not) fragile at any given historical moment, and context-specific strategies for responding in ways that legitimately comport (and are perceived as such by domestic actors) with specific country characteristics, and how those change over time. It is increasingly recognized that prevailing theories, measures and strategies guiding international agencies' responses to fragile and conflict-affected states are inadequate, and that fresh thinking and doing is thus required.

This paper has attempted to take small steps in this direction. In keeping with its own stated principles, its offerings are made in the spirit of encouraging open and ongoing debate on an issue that is a twenty-first century incarnation of an enduring problem-how to give and how to receive in seemingly desperate situations. 19 Responding constructively and legitimately to the challenges of fragile states is not a problem for which there is an answer awaiting to be derived but rather one requiring answers as varied as the specific contexts in which they are experienced. PDIA offers an emerging approach to creating robust spaces wherein specific development problems (among many) can be nominated and prioritized by teams of local actors, and various responses to them tried and refined. Some (perhaps many) of these responses will prove unsatisfactory, even a complete failure; the forces against which they are arrayed are many and powerful, and time horizons are usually short. But learning a complex skill of any kind-a musical instrument or foreign language, calculus or juggling-requires persistence and tolerance for initial mistakes, and this is true for organizations as much as it is for individuals. Implementing key public policy actions is deceptively hard, and many countries struggle to carry out even routine logistical tasks, such as delivering the mail (Chong et al. 2012), let alone more difficult ones (such as criminal justice or land administration).

PDIA is not itself the answer to this challenge; it is one approach for addressing those aspects of problems in fragile states that fundamentally cannot be addressed by importing solutions from abroad. In particular, PDIA provides a plausibly entry point into those exceptionally 'complex' problems for which solutions emerge through local, equitable political contests (or 'good struggles' 20 that imbue them with the necessary legitimacy, content and support. It is this approach to (or theory of) institutional change which gives rise to the proposals outlined above for rethinking how and on what basis fragile states are classified, and what, in turn, can be done to optimally support and sustain the (long) passage out of fragility.

\section{References}

Adler, D., C. Sage, and M. Woolcock (2009). 'Interim Institutions and the Development Process: Opening Spaces for Reform in Cambodia and Indonesia'. Working Paper No. 86, Manchester: Brooks World Poverty Institute, University of Manchester.

Allen, M. S. Dinnen, D. Evans, and R. Monson (2013). 'Justice Delivered Locally: Systems, Challenges and Innovations in Solomon Islands'. Research Report, Justice for Poor. Washington, DC: World Bank.

accommodate situations in which those factors that successfully move a country out of conflict and fragility may not be just the opposite of those that return it to (or keep it in) that unhappy state?

19 I borrow this coupling from the opening chapter of Robert Klitgaard's classic book Tropical Gangsters, which is called 'Giving and Receiving'. One must also appreciate that geo-strategic concerns are typically uppermost in policy makers' minds when considering the plight of fragile states, and that academic research on the subject appears to have made remarkably little impact on shaping the tone and terms of debate (see Paris 2011).

20 This formulation comes from Adler et al. (2009). 
Andrews, M. (2008). 'The Good Governance Agenda: Beyond Indicators Without Theory'. Oxford Development Studies, 36(4): 379-407.

Andrews, M. (2013). The Limits of Institutional Reform in Development: Changing Rules for Realistic Solutions. New York: Cambridge University Press.

Andrews, M., L. Pritchett, and M. Woolcock (2013). 'Escaping Capability Traps Through Problem-driven Iterative Adaptation (PDIA)'. World Development, 51(11): 234-44.

Barma, N., E. Huybens, and L. Viñuela (2013). 'Institutions Taking Root: Building State Capacity in Challenging Contexts'. Mimeo. Washington, DC: World Bank.

Bayly, C.A. (2004). The Birth of the Modern World, 1780-1914: Global Connections and Comparisons. Malden, MA: Blackwell.

Bulman, T., and A. Batten (2012). 'How Well do PNG's Policies and Institutions Turn Resources into Broad-based Growth? Insights from the Multilateral Banks' Assessment'. Papua New Guinea Policy Issues. World Bank and Asia Development Bank, Joint Policy Brief.

Chong, A., R. La Porta, F. Lopez-de-Silanes, and A. Shleifer (2012). 'Letter Grading Government Efficiency’. Working Paper No. 18268. Cambridge, MA: NBER.

de Weijer, F. (2013). 'A Capable State in Afghanistan: A Building without a Foundation?'. WIDER Working Paper No. 2013/063. Helsinki: UNU-WIDER.

Douglas, M. (1986). How Institutions Think. Syracuse, NY: Syracuse University Press.

Eizenstat, S.E., J.E. Porter, and J.M. Weinstein (2005). 'Rebuilding Weak States'. Foreign Affairs, 84(1): 134-46.

Fukuyama, F. (2004). State Building: Governance and World Order in the 21 ${ }^{\text {st }}$ Century Ithaca. NY: Cornell University Press.

G7+ (2013). 'Note on the G7+ Fragility Spectrum'. Launched in Kinshasa, Democratic Republic of Congo, 27 November.

Ghani, A., and C. Lockhart (2009). Fixing Failed States: A Framework for Rebuilding a Fractured World. New York: Oxford University Press.

Goddard, M. (2010). 'Justice Delivered Locally: Solomon Islands'. Justice for the Poor Working Paper. Washington, DC: World Bank.

Goertz, G., and J. Mahoney (2012). A Tale of Two Cultures: Qualitative and Quantitative Research in the Social Sciences. Princeton, NJ: Princeton University Press.

Gupta, A. (2012). Red Tape: Bureaucracy, Structural Violence and Poverty in India. Durham, NC: Duke University Press.

Hall, M., N. Menzies, and M. Woolcock (2014). 'From HiPPOs to "Best Fit" in Justice Reform: Experimentalism in Sierra Leone'. In D. Marshall (ed.), The International Rule of Law Movement: $A$ Crisis of Legitimacy and the Way Forward. Cambridge, MA: Harvard University Press.

Helman, G.B., and S.R. Ratner (1992). 'Saving Failed States’. Foreign Policy, 89: 3-20.

Hirschman, A. (1967). Development Projects Observed. Washington, DC: The Brookings Institution.

Jerven, M. (2013). Poor Numbers: How We Are Misled by African Development Statistics, and What to Do About It. Ithaca, NY: Cornell University Press.

Larson, G., P. Ajak, and L. Pritchett (2013). 'South Sudan's Capability Trap: Building a State with Disruptive Innovation' WIDER Working Paper No 2013/120. Helsinki: UNU-WIDER 
Lieberson, S. (1985). Making it Count: The Improvement of Social Research and Theory. Berkeley, CA: University of California Press.

Milante, G. (2013). 'An Inductive Approach to Identifying Fragility'. Mimeo. Washington, DC: World Bank.

OECD (2012). Fragile States 2013: Resource Flows and Trends in a Shifting World. Paris: OECD/DAC International Committee on Conflict and Fragility.

Paris, R. (2011). 'Ordering the World: Academic Research and Policymaking on Fragile States'. International Studies Review, 13: 58-71.

Pascale, R., J. Sternin, and M. Sternin (2010). The Power of Positive Deviance: How Unlikely Innovators Solve the World's Toughest Problems. Boston: Harvard Business School Press.

Porter, D., D. Isser, and L.-A. Berg (2013). 'The Justice-Security-Development Nexus: Theory and Practice in Fragile and Conflict-affected States'. Hague Journal on the Rule of Law, 5(2): $310-28$.

Porter, D., C. Wescott, M. Andrews, and J. Turkewitz (2011). 'Public Financial Management and Procurement in Fragile and Conflicted Settings'. International Public Management Journal, 14(4): 369-94.

Pritchett, L., M. Woolcock, and M. Andrews (2013). 'Looking Like a State: Techniques of Persistent Failure in State Capability for Implementation'. Journal of Development Studies, 49(1): $1-18$.

Scott, J. (1998). Seeing Like a State: How Well-Intentioned Schemes to Improve the Human Condition Have Failed. New Haven, CT: Yale University Press.

Stewart, F., and G.K. Brown (2009). 'Fragile States'. Working Paper No. 51. Oxford: Centre for Research on Inequality, Security and Ethnicity (CRISE), Oxford University.

UNDP (2009). Users' Guide to Measuring Fragility. New York: United Nations Development Programme, and the German Development Institute.

Woolcock, M. (2013). 'Using Case Studies to Explore the External Validity of Complex Development Interventions'. Evaluation, 19(3): 229-48.

Woolcock, M., and P. Garrity (2013). 'Locating Problem-Driven Iterative Adaptation (PDIA) in the Landscape of Contemporary Ideas for Institutional Reform'. Mimeo. Cambridge, MA: Harvard Kennedy School.

World Bank (2001). Breaking the Conflict Trap. New York: Oxford University Press.

World Bank (2011). World Development 2011: Conflict, Security and Development. Washington, DC: World Bank.

World Bank (2013). World Bank Group Assistance to Low-Income Fragile and ConflictAffected States: An IEG Evaluation' Washington, DC: World Bank, Independent Evaluation Group.

Zartman, I. (ed.) (1995). Collapsed States: The Disintegration and Restoration of Legitimate Authority. Boulder, CO: Lynne Rienner Publishers. 
Annex 1: FY 15 harmonized list of states in 'failed situations' (as determined by the World Bank)

\begin{tabular}{|c|c|c|c|c|c|}
\hline Country & WB CPIA Score & $\begin{array}{l}\text { ADB/ADB CPUA } \\
\text { Score }\end{array}$ & Harmonized Average & $\begin{array}{c}\text { Political and Peace-Building } \\
\text { Missions }\end{array}$ & Peace-keeping Missions ${ }^{\alpha}$ \\
\hline \multicolumn{6}{|l|}{ IDA Eligible } \\
\hline Afghanistan & 2.650 & 2.842 & 2.7 & $P$ & Pk \\
\hline Burundi & 3.242 & 3.409 & 3.3 & $P$ & \\
\hline Central African Republic & 2.500 & 2.262 & 2.4 & $P$ & \\
\hline Chad & 2600 & 3.247 & 2.9 & & \\
\hline Comoros & 2.758 & 2.392 & 2.6 & & \\
\hline Congo, DR & 2.883 & 3.290 & 3.1 & & $\mathrm{Pk}$ \\
\hline Cote d'lvoire & 3.183 & 3.342 & 3.3 & & $P k$ \\
\hline Eritrea & 1.992 & 1.933 & 2.0 & & \\
\hline Guinea-Bissau & 2.525 & 2.644 & 2.6 & $P$ & \\
\hline Haiti & 2.833 & - & 2.8 & & Pk \\
\hline Kiribati & 2.908 & 2.983 & 2.9 & & \\
\hline Kosovo & 3.592 & - & 3.6 & & $P k$ \\
\hline Liberia & 3.125 & 3.492 & 3.3 & & Pk \\
\hline Madagascar & 3.017 & 3.162 & 3.1 & & \\
\hline Mali & 3.383 & 3.775 & 3.6 & & Pk \\
\hline Marshall islands & 2.642 & 2.967 & 2.8 & & \\
\hline Micronesia, FS & 2.692 & 2.883 & 2.8 & & \\
\hline Myanmar & 2.950 & - & 3.0 & & \\
\hline Sierra Leone & 3.267 & 3.447 & 3.4 & $P$ & \\
\hline Solomon islands & 2.933 & 3.308 & 3.1 & & \\
\hline Somalia & - & 1.104 & 1.1 & $P$ & \\
\hline South Sudan & 2.092 & 2.279 & 2.2 & & $\mathrm{Pk}$ \\
\hline Sudan & 2.358 & 2.620 & 2.5 & & Pk \\
\hline Togo & 2.967 & 3.093 & 3.0 & & \\
\hline Tuvalu & 2.767 & 3.050 & 2.9 & & \\
\hline Yemen & 2.992 & - & 3.0 & & \\
\hline \multicolumn{6}{|l|}{ Territories } \\
\hline West Bank \& Gaza & - & - & & $P$ & \\
\hline \multicolumn{6}{|l|}{ Blend } \\
\hline Timor-Leste & 3.058 & 3.317 & 3.2 & & $P k$ \\
\hline Zimbabwe & 2.258 & 2.173 & 2.2 & & \\
\hline \multicolumn{6}{|l|}{ Middle Income } \\
\hline Bosnia \& Herzegovina & - & - & - & $P$ & \\
\hline Iraq & - & - & - & $P$ & \\
\hline Libya & 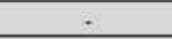 & - & - & $P$ & \\
\hline Syria & - & - & - & $P$ & \\
\hline \multicolumn{6}{|c|}{ 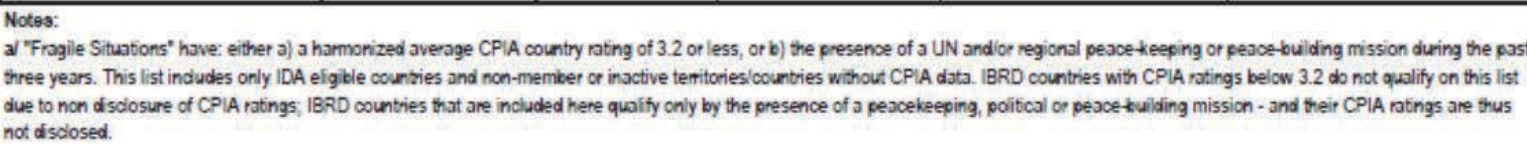 } \\
\hline \multicolumn{6}{|c|}{$\begin{array}{l}\text { b/ Specifically defined as the presence of a UN andior regional (e.g. AU, EU, OAS) peuce-buliding and political mission in this country in the last three years. [sources: UN DPKO website, AU } \\
\text { website, EC website]. }\end{array}$} \\
\hline $\begin{array}{l}\text { c/ Specifically defined as the p } \\
\text { operations. [Sources: UN DPh }\end{array}$ & $\begin{array}{l}\text { UN andlor regional (e } \\
\text { AU website, EC webs: }\end{array}$ & $\begin{array}{l}\text { AU, EU, OAS, NATO) } \\
\text { OSCE website]. }\end{array}$ & peace-keeping operation in & his country in the last three years, w & the exclusion of border monitoning \\
\hline
\end{tabular}

Source: World Bank website on Fragility, Conflict and Violence;

http://siteresources.worldbank.org/EXTLICUS/Resources/511777-1269623894864/FY15FragileSituationList.pdf (Accessed June 2014) 
Annex 2: Examples of trajectories of CPIA change in selected fragile states

Wcutal and Extrapolations of CPI for CENTR L

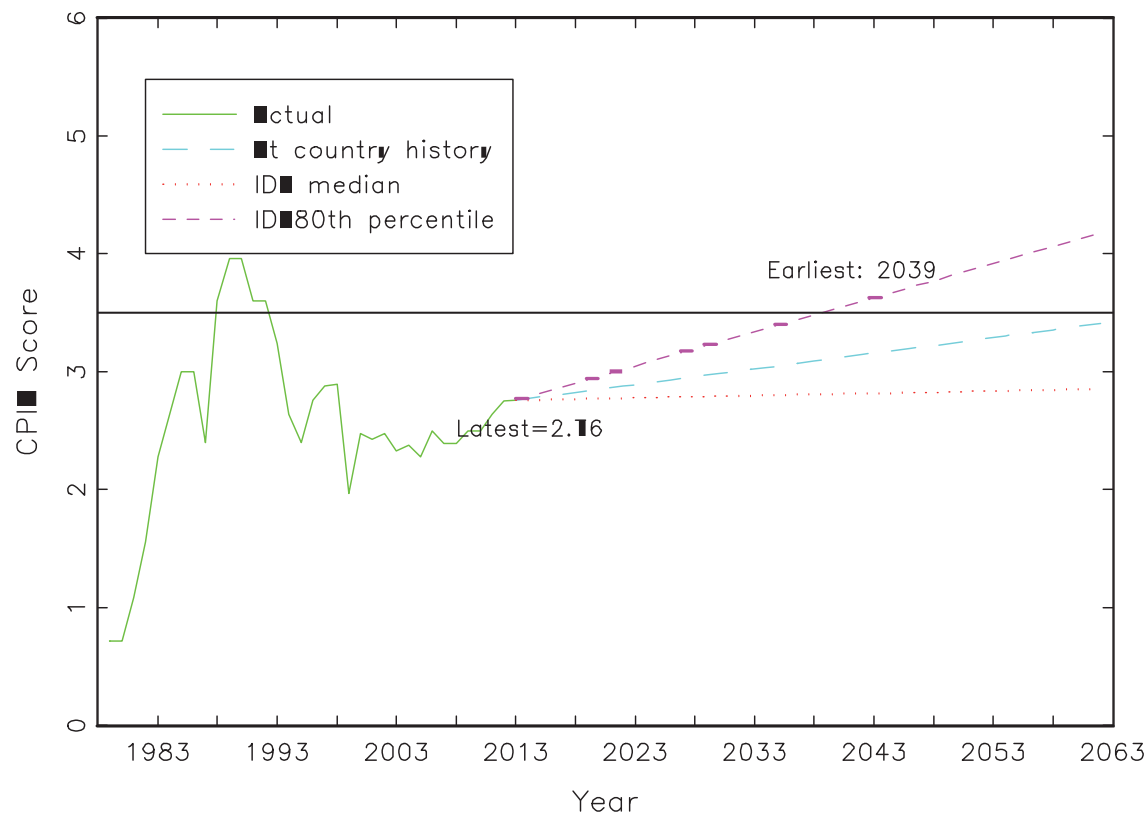

-cutal and Extrapolations of CPI for GUINE-B

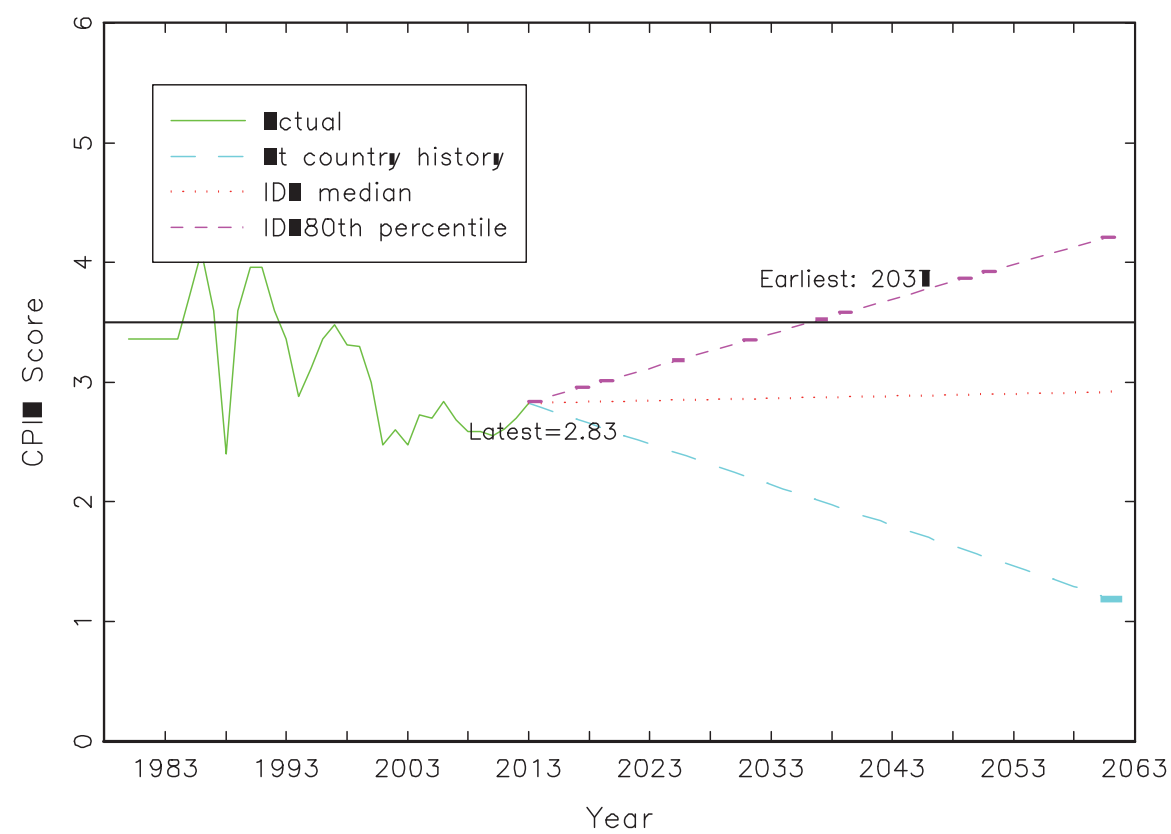

Source: Graphs prepared by Lant Pritchett. 